\title{
GOUT AND ALEUKAEMIC LEUKAEMIA IN A BOY AGED FIVE
}

\author{
BY \\ C. WILFRED VINING, M.D., F.R.C.P., \\ AND \\ J. G. THOMSON, M.B., Сh.B.(ABerd.). \\ (From the Leeds General Infirmary.)
}

The case we are about to describe is that of a small boy who, for a period of seven months suffered from a severe anaemia, glandular enlargement and symmetrical multiple arthritis. At post mortem there were found extensive gouty deposits in the joints and subcutaneous tissues, and microscopical examination of the organs showed leukaemic infiltrations of the kidneys and liver.

\section{Case record.}

John T., aged three-and-a-half years at the onset of his illness, was quite well until June, 1933. He then gradually became listless and lost weight. He became easily tired and tended to fall rather frequently. During July the parents noticed a swelling under his chin and he came under the care of Dr. Macvie, of Elland. Dr. Macvie found extensive enlargement of the cervical glands and noticed that the child was anaemic. Blood films were taken and the pathologist's report (Dr. Denton Guest, of Huddersfield) on these films was as follows :- ' Neutrophil polymorphs 43 per cent.; lymphocytes 51 per cent.; eosinophils 1 per cent.; basophils 2 per cent.; transitional cells 3 per cent. Many of the lymphocytes are of immature type and do not stain well.'

He was treated for a possible tuberculous infection and there was some improvement. He was able to keep about until October 13, when he complained of pain in the ankles which prevented further walking. It was noticed that both ankles were swollen. About this time his stools became frequent and were pale and frothy, and the possibility of coeliac disease was considered. His urine became ' thick like milk, this being due to an intense phosphaturia. During the following weeks other joints became involved and all were intensely painful. He was seen by one of us on November 26, 1933, and the following day he was admitted to the Leeds General Infirmary.

CONDition on November 27:-The child was wasted, fretful and ill. Weight, $28 \mathrm{lb}$. There was an intense anaemia. His ankles, knees, wrists, elbows and the small joints of his hands and feet were swollen and extremely painful when passively moved (fig. 1). The tip of the spleen was palpable and the liver was enlarged two finger-breadths. His general appearance suggested a severe case of Still's disease, although it was noted at the time that the pain was rather more intense and the anaemia more pronounced than that found in the acute rheumatoid arthritis of childhood.

Examination of the heart showed numerous haemic bruits. The urine by the usual ward tests was normal and clear. The tuberculin tests and Wassermann 
reaction were negative. The report of the examination of the blood was as follows :Red cells 1,040,000 per c.mm.; haemoglobin 26 per cent.; leucocytes 2,950 per c.mm.; colour index 1.3. The red cells stained well and showed some irregularity in size, many of them being definitely larger than normal. There were no nucleated reds. Differential leucocyte count:-neutrophil polymorphs $60 \cdot 5$ per cent.; lymphocytes $\mathbf{3 6} \cdot 0$ per cent.; monocytes 3.5 per cent.

$\mathrm{X}$-ray examination of the joints and limbs showed nothing unusual apart from the increased shadowing about the joints consistent with a chronic inflammatory condition with much periarticular thickening.

An attempt was made to improve his condition by the treatment of the anaemia with liver extract, and he was given small doses of guaiacol carbonate with iodide of potassium and syrup glycerophos. co. Avoleum. $m \mathrm{v}$, twice daily, was also given. During the following weeks the degree of pain in the joints and also the amount of swelling was much less, and a further blood-count on December 11 gave the following result:- Red cells $2,050,000$ per c.mm.; haemoglobin 34 per cent.; leucocytes 8,350 per c.mm.; colour index 0.8. The red cells showed irregularity in size and staining and there were occasional megalocytes. Halometer reading, 6.9. The differential count showed nothing unusual.

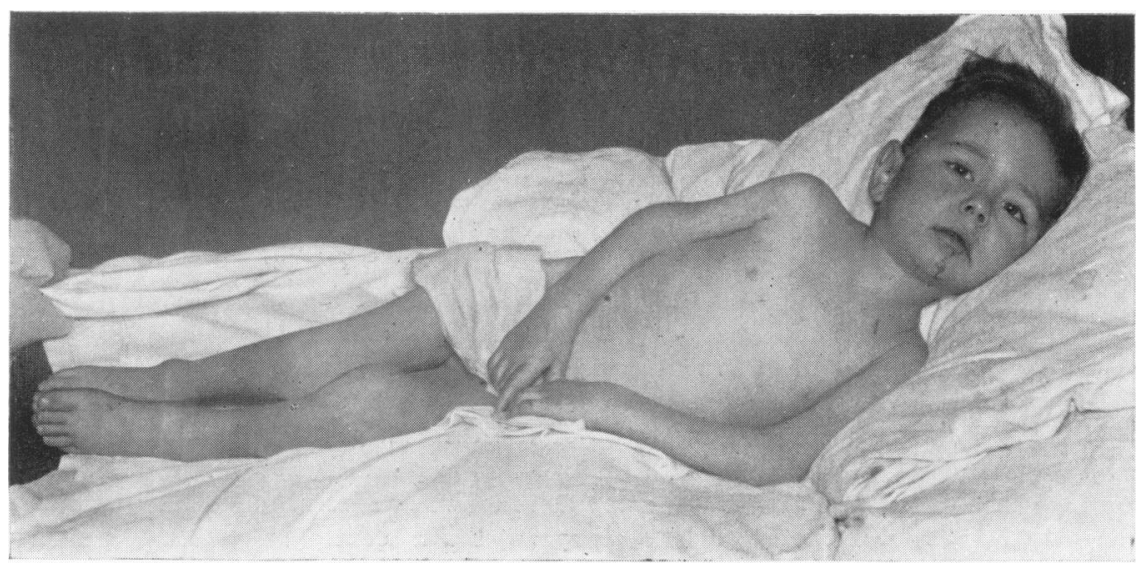

Fig. 1.-The patient on admission to the Leeds General Infirmary.

A third count undertaken a fortnight later showed almost identical figures, but there was now a notable irregularity in the size and shape of the red cells and there was a well-marked megalocytosis. Punctate basophilia was very frequent and nucleated red cells, both normoblasts and megaloblasts, were seen in considerable numbers. As compared with the first examinations it would seem that there was now a good deal of increased marrow activity.

During the last few weeks of the illness there was noticed about the elbows, wrists and knees multiple subcutaneous nodules, which were looked upon as similar to those associated with the rheumatic state of childhood (fig. 2). It was realised at the time that such nodules are not usually found apart from the true rheumatic affections of childhood, but it was thought that their presence supported the belief that the child was suffering from a streptococcal infection of the rheumatic group. Towards the end the liver became greatly enlarged and the spleen was just palpable. There was an irregular pyrexia during the first and last four of the nine weeks he was in the Infirmary. During the whole time he was under observation there was a very obvious generalized glandular enlargement, more especially in the cervical regions and the axillae. His illness terminated with laryngeal obstruction due to oedema following suppuration in the left sterno-clavicular joint, and he died sevenand-a-half months from the onset of his illness. 
FAMILY HISTORY. The boy's paternal great-grandmother suffered from gout for many years. The gouty transmission appears to have been passed to the child through his father from two sources, as in addition to the transmission from the great-grandmother her husband's brother also suffered from gout. The only other history of note is that in connection with the child's maternal uncle who died in mid-life from pernicious anaemia.

The post-mortem examination was made 9 hours after death by Professor M. J. Stewart.

External apparances. The body was emaciated and the abdomen was relatively enlarged. Over both knees and elbows there were numerous small subcutaneous shotty nodules which proved on section to be white chalky deposits of various sizes up to half-an-inch in diameter. Similar deposits were present in the periarticular tissues. The wrists, metacarpo-phalangeal and first inter-phalangeal joints were similarly affected, while round the ankles were present large chalky masses over both

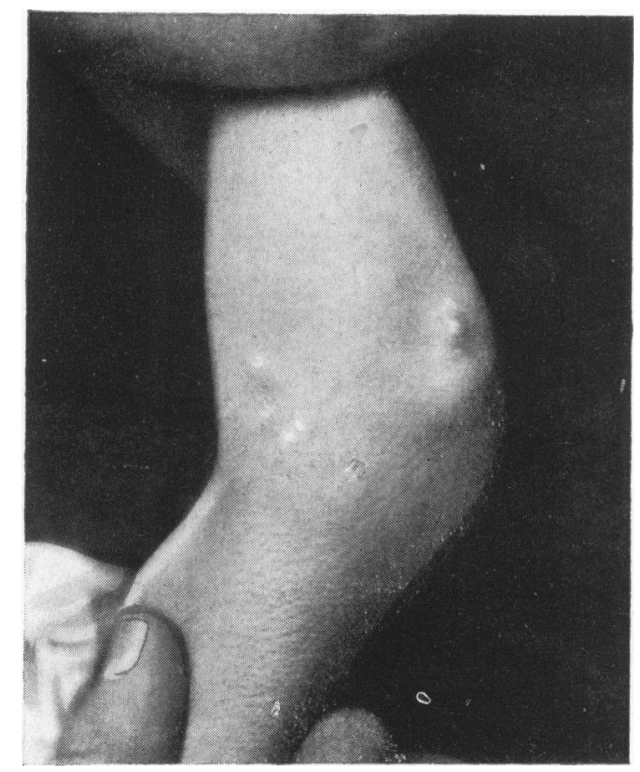

Fig. 2.-Nodules on the elbow.

internal and external malleoli, and the extensor tendon sheaths were covered in front by a flattened mass of the same chalky material. The fingers and toes showed numerous tophi.

JoINTs. The elbow joints showed advanced lesions of a remarkable kind. The interior of the joint, except the actual articular surface, was lined by a thick deadwhite layer of dried, friable material more closely resembling white lead than anything else. The ankle joints were equally severely affected, as were the small joints of the hands and feet. The shoulder and knee joints showed what appeared to be an earlier stage of the same lesion, their capsules being lined by an incomplete layer of the same material. They also contained much tenacious glairy fluid, while the elbow and ankle joints were quite dry. The hip joints were free from gouty deposition. The left sterno-clavicular joint was slightly affected, the right not at all. There was no evidence of involvement of the spinal articulations.

KIDNEYs. These appeared slightly enlarged, weighing $4 \frac{1}{2}$ oz. The capsules striped readily exposing a smooth surface dotted with white and yellowish-white streaks and patches. On section the organs were pale with very indistinct markings, so that 
it was difficult to differentiate cortex and medulla with any certainty. The greater part of the cut surface of both organs showed radial white and yellowish-white streaks affecting mainly the medullary pyramids, through present, in cortex as well.

SPLEEN. Weight, $2 \frac{1}{2}$ oz. Some areas of congestion were present on section.

Lrver. Weight, $27 \mathrm{oz}$. This was pale-yellow and fatty-looking.

Larynx. There was a notable oedema of the glottis, especially of the ary-epiglottic folds.

Lungs. Some superficial collapse was found.

The other organs, including brain, showed no abnormal findings.

Microscopic examination.-KIDNEy. Scattered throughout the kidney substance, both in cortex and in medulla, were extensive leukaemic infiltrations. These infiltrations were practically confluent in the cortex, where only occasional groups of tubules had escaped. The infiltrating cells had the morphology and staining reactions of ordinary lymphocytes, with small spherical hyperchromatic nuclei, round

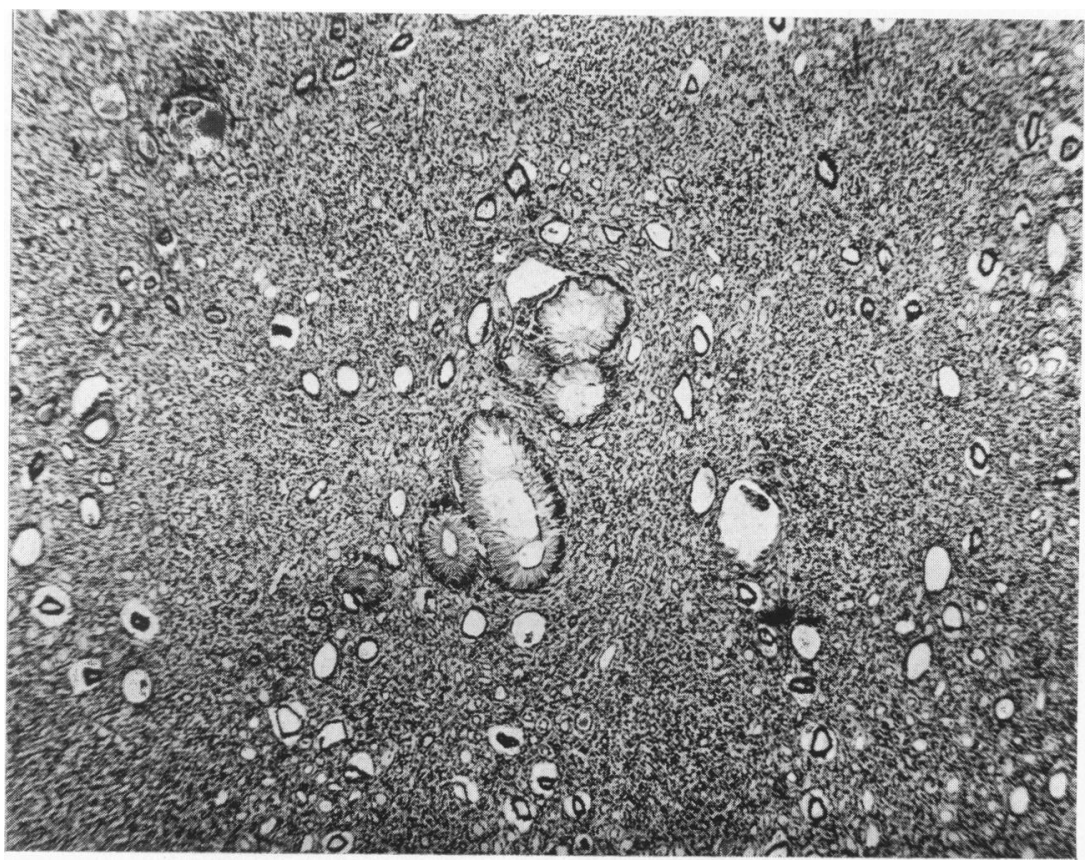

FIG. 3.-Kidney. Four gouty deposits in the medulla. The interstitial tissues are infiltrated by lymphocytes. Low power.

which a little cytoplasm could occasionally be distinguished. In the denser parts of the infiltrations no renal tissue could be identified; elsewhere the renal elements were widely separated and apparently unaffected by the cellular infiltrations. The glomeruli appeared normal apart from some dilatation of the glomeruli spaces; the secretory tubules showed moderately severe degenerative changes, with here and there loss and sometimes absence of nuclear staining and fusion and granularity of cytoplasm. In the medulla the leukaemic infiltrations were not so marked, probably because the larger proportion of connective tissue normally present in the medulla limits its distensibility. The gouty deposits were present in both cortex and medulla though rather more frequent in the latter. They appeared in paraffin sections as circular or oval areas all more or less of similar size, surrounded by a continuous zone of endothelioid cells at right angles to the circumference, with 
cellular processes radiating into the mass like the conventional representation of the sun (fig. 3). In a fair percentage of these, giant cells of the usual foreign body type lay at the periphery replacing a group of these endothelioid cells (fig. 4). More rarely a smaller gouty focus can be seen engulfed by a larger giant cell. The uratic material had been dissolved out in the watery fixative (1 per cent. formalin saline) used, but the long processes of the endothelioid cells projecting into the centre of the mass indicated by the spaces between them that the material had an acicular crystalline structure. In the centre of many of the deposits, especially the larger, there were circular or oval thin empty rings of haematoxylin stained granular material, indicating that a small percentage of calcium salts were contained in the uratic material. In others an eosinophilic protein exudate occupied the whole site of the gouty deposit. These deposits were all much larger than the urinary tubules, and it is difficult to say whether they originated in tubules as in the

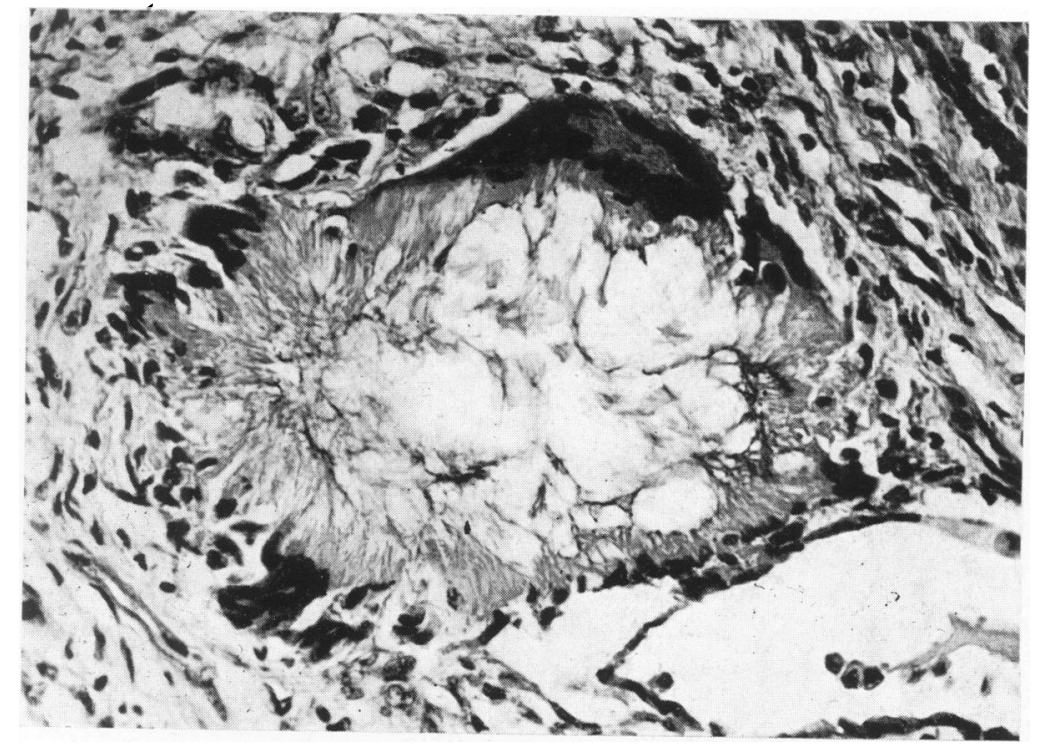

FIG. 4.-Kidney. A high power view of a gouty deposit, showing the endothelioid and foreign body giant cell reaction.

uric-acid infarcts of infants, or in the interstitial tissues as in true gout; but the fact that they were mainly white in the naked-eye specimen strongly suggests that they had an extra-tubular origin, as the uric-acid infarcts of children are formed in the tubules and are coloured yellowish by the urinary pigments. In one or two cases the deposits could be seen protruding into a dilated tubule, but this is most probably the result of mechanical penetration from the increasing size of the deposits. In all cases the reaction to the presence of the gout consisted of endothelioid cells and giant cells, granulation tissue or fully formed fibrous tissue being nowhere in evidence.

Liver. Here the leukaemic infiltrations were of the same cellular nature as those in the kidney, but they were confined to the dilated portal tracts and the portions of the lobules immediately surrounding them, every portal tract being affected and roughly one-quarter of the total liver substance being composed of the leukaemic infiltrations. These stopped abruptly at the peripheral zones of the lobules, and the parenchymatous tissue was not appreciably invaded. The liver rells showed a moderate degree of fatty change, mainly in the peripheral zones; and 
the sinusoids were distended, especially in the centre of the lobules, but contained little blood and no excess of lymphocytes. The Kupfer cells were not unduly prominent.

SPLEen. There were no leukaemic infiltrations as such in the spleen, but here and there in the pulp were small focal accumulations of lymphocytes, with occasional plasma cells. Macrophages were scanty; there was no excess of haemosiderin. The Malpighian bodies were small for a child of this age, being without germinal centres and sparse in cells.

The other internal organs gave no histological findings of note.

Jornss. As in the kidney, the gouty material had dissolved in the watery fixative employed; its site is indicated by the haematoxylin staining of the calcium salts or by the protein material that accompanied it. It had often caused practically no reaction when lying free in the joint cavity; it could be removed by hand or washed away in a stream of running water, leaving a smooth and glistening synovial membrane behind. At the edges of the joints and in the tendon sheaths a well-

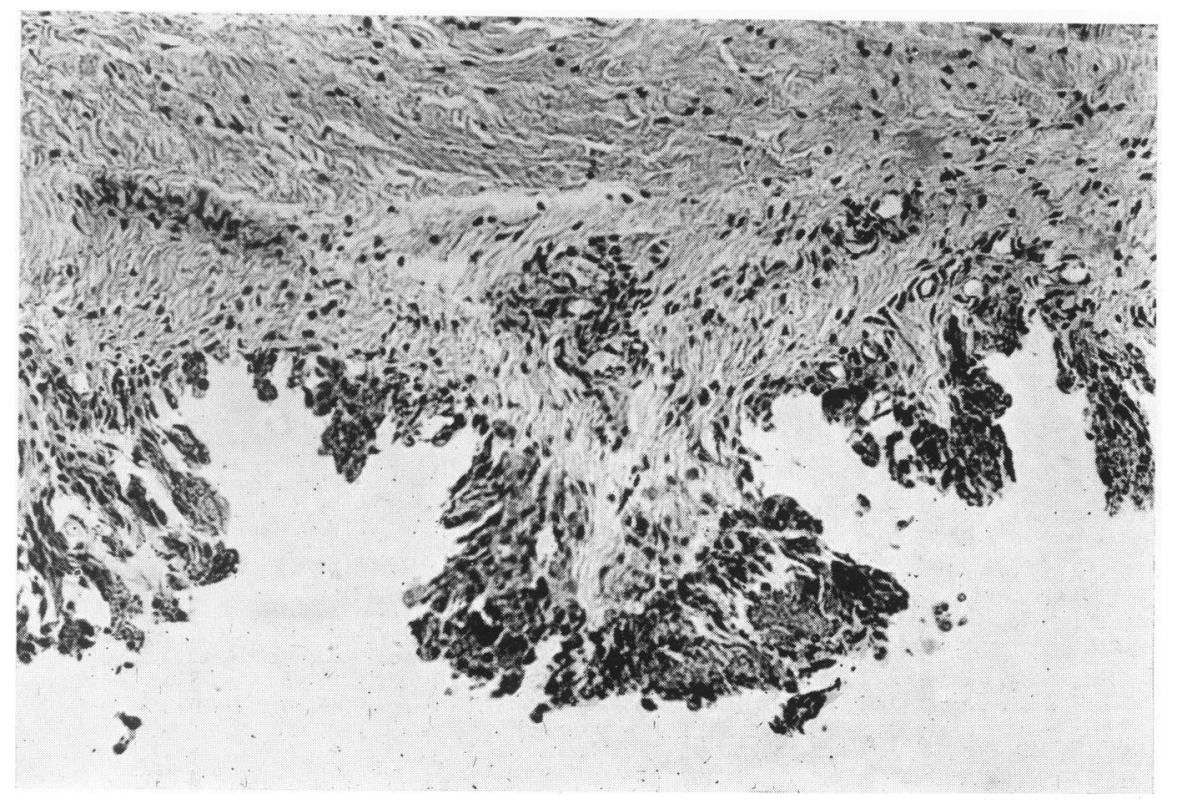

FIG. 5. - Synovial membrane of elbow joint. It is lined by a continuous layer of endothelioid cells and foreign body giant cells. Note the superficial nature of the cellular reaction.

marked cellular reaction had been called out, of the same nature as in the kidney. The synovial membrane was covered by a continuous layer of giant cells of foreign body type, with occasional endothelioid cells. This reaction was a very marked one but was strikingly superficial; the only reaction deeper than this single layer being a few foci of lymphocytic infiltration in the connective tissue immediately underneath (fig. 5). The amount of calcium salts in the uratic material showed great variability; it was generally scanty and showed as a diffuse, faint, bluish staining, but more rarely it was bluish-black, almost as dark as ordinary calcification. In those latter areas the cellular reaction was no more pronounced.

Skeletal MUSCLES. In the microscopic sections of the joints and tendon sheaths, portions of skeletal muscles often appeared and these showed marked atrophic and degenerative changes. The fibres were either much shrunken and filled only a small 
part of the sarcolemma sheaths or else were swollen, glossy and homogeneous with partial or complete loss of the transverse striations. These changes were marked in all the sections, including muscles near all the joints of the extremities; but it was difficult to assess how much of this was due to disuse atrophy and how much was due to the proximity of the gouty deposits, as control pieces of muscle away from the joints were not taken for examination.

Ghemical examination.-Dr. Fowweather reports that the gouty material (dried) from the knee and ankle joints contained 64.1 per cent. of sodium mono-urate.

\section{Discussion.}

From the report given there can be no doubt that we are dealing with a case of true gout and gout of an extensive nature. Gout in children is a rare condition and the only cases we have been able to find without attempting to analyze the literature are five in number. These comprise two in girls aged seven and eight $\left(\right.$ Garrod $\left.^{2}\right)$, a child aged three-and-a-half (Stilli), an adult case who had his first attack in the big toe when aged eight $\left(\right.$ Scudamore $^{6}$ ), and a similar case aged fifty, whose first attack occurred at the age of eleven (Duckworth ${ }^{1}$ ). These cases, however, are quite different from our own; they are merely examples of ordinary gout commencing in early life, and not a generalized disease ending fatally after a short duration. We had imagined that this case would be unique, both in the youthfulness of the patient and the extent of the lesions, but we find that von Schopf ${ }^{5}$ recently reported a case in an even younger subject, aged five-and-a-half weeks. The case is so similar to our own that it merits a short description.

The infant was the third child of healthy parents, both of whose families were free from a family history of gout. The child vomited after nearly every meal and the mother noticed hard thickening on the backs of its hands when it was three weeks old. These rapidly increased in size, obvious involvement of the joints could be seen, and the gouty deposits increased with rapidity until the death of the infant from bronchopneumonia at the age of six weeks. The post-mortem examination revealed a condition similar to the case just described and von Schopf's photomicrographs might well have been used to illustrate this paper. In discussing his case von Schopf emphasizes the fact that usual ' causes of gout' could be excluded, the child being breast-fed throughout, and that it illustrates the importance of endogenous purines in the aetiology of gout. There were no leukaemic infiltrations in his case, and he inclined to the view that the features of allergy present, eczema, low temperature, hypermotility of the intestine with increased stools and mucus, support the allergic theory of the pathogenesis of gout.

It is extraordinary that a rare case of gout in a child should be complicated by another rare condition, aleukaemic leukaemia. Leukaemia without leucocytosis has been recognized only in recent years and Hyland ${ }^{3}$ reports three typical cases similar to our own. Their ages were five, five-anda-half, and eight-and-a-ahalf, with total leucocyte counts varying from 1,450 to 8,600 per c.mm., the differential counts showing a percentage of lymphocytes from 22 to 96. A severe anaemia was present in all three cases, with a high colour index, and normoblasts were generally present. All three died, an autopsy being performed on two and showing histologically leukaemic infiltrations of lymphatic type in kidneys and liver. 
When this case was described by one of us at a meeting of the British Paediatric Association in May, 1934, the diagnosis of aleukaemic leukaemia was questioned by some on the length of the history (seven months), cases of lymphatic leukaemia of such duration being outside their experience. We would only state that two of Hyland's cases were of long duration, one of seven months and the other of fifteen months, the duration dating, as in our case, from the beginning of symptoms. Apart from this the histology of the liver and kidneys puts the matter beyond all doubt.

The occurrence of gout in association with leukaemia has never, so far as we are aware, been reported in a child. Its association with other diseases has, however, been reported on many occasions, and Roberts and Rose Bradford $^{4}$ refer to the development of gout in the adult during the course of myelogenous leukaemia. They point out that in leukaemia the amount of uric acid excreted in the urine is greatly increased. In the cases mentioned by them the gout was in existence before the development of the leukaemia, and so far as we have been able to ascertain no case has previously been reported of gout supervening as a clear sequence of a leukaemia. Also it would appear that when the association has been reported the leukaemia has always been of the myelogenous type.

We would suggest that in our case the leukaemic state was the primary condition and occurring, as it did, in a child whose ancestors were gouty, it led to the precipitation of an acute generalized deposit of urates. Uratosis is seen only in gout and is, indeed, pathogmonic of gout. The association of uric acid with nuclein is clear, uric acid being an oxypurin. The decomposition of nuclein in the body leads to the formation of xanthins and hypoxanthins and these are in part oxidised in the body to uric acid and excreted as such. The explanation seems to be obvious that in the leukaemic state there is available large amounts of nuclein from the breakdown of immature white cells, and when leukaemia arises in the subject carrying the latent tendency to gout the development of uratosis is not unlikely.

\section{REFERENGES.}

1. Duckworth, D., A Treatise on Gout, London, 1889, 326.

2. Garrod, A., Gout and Rheumatic Gout, London, 1876, third edition, 211.

3. Hyland, C. M., Am. J. Dis. Child., Chicago, 1930, XXXIX, 59.

4. Roberts, W., \& Rose Bradford, J., System of Medicine (Allbutt and Rolleston), London, 1907, III, 123.

5. von Schopf, E. M., Klin. Wchnschr., Berlin, 1930, IX, 2148.

6. Scudamore, C., Gout and Gravel, 1823, 63.

7. Still, G. F., Common Disorders and Diseases of Childhood, Oxford, 1927, fifth edition. 